\title{
Heterogeneous Catalytic Performance and Stability of Iron-Loaded ZSM-5, Zeolite-A, and Silica for Phenol Degradation: A Microscopic and Spectroscopic Approach
}

\author{
Yasaman Ghaffari ${ }^{1,2}$, Nishesh Kumar Gupta ${ }^{1,2}$, Jiyeol Bae ${ }^{2}$ and Kwang Soo Kim ${ }^{1,2, *}$ \\ 1 University of Science and Technology (UST), Daejeon 34113, Korea; yasaman@kict.re.kr (Y.G.); \\ guptan@kict.re.kr (N.K.G.) \\ 2 Department of Land, Water, and Environment Research, Korea Institute of Civil Engineering and Building \\ Technology (KICT), Goyang 10223, Korea; baejiyeol@kict.re.kr \\ * Correspondence: kskim@kict.re.kr
}

Received: 25 September 2019; Accepted: 11 October 2019; Published: 15 October 2019

\begin{abstract}
In this study, we compared the performances of three iron-containing crystalline and amorphous catalysts, that is, Fe-Zeo-A, Fe-ZSM-5, and Fe-silica, respectively, for the degradation of phenol in an aqueous solution. Catalytic activity for the degradation of phenol was assessed by heterogeneous photolysis, Fenton, and photo-Fenton oxidation. All catalysts exhibited higher activity in the photo-Fenton process. In addition, the catalyst stability was evaluated by the estimation of the iron loss and structural variations after the oxidation processes. Results revealed that Fe-silica and Fe-ZSM-5 exhibit higher catalytic activity ( $100 \%$ phenol removal), while only $64 \%$ of phenol removal over Fe-Zeo-A was observed. Moreover, among all catalysts, Fe-ZSM-5 exhibited higher stability with low iron leaching, attributed to the uniform distribution of bonded Fe in the crystalline framework and narrow channels. On the contrary, amorphous Fe-silica exhibited higher iron leaching due to the presence of isolated iron species in the structure, leading to the partial involvement of a homogeneous reaction during the degradation of phenol. The structural stability of Fe-based catalysts was examined using microscopic and spectroscopic techniques.
\end{abstract}

Keywords: heterogeneous catalysts; iron; phenol; photo-Fenton oxidation; spectroscopy

\section{Introduction}

Phenol has been classified as one of the most harmful environmental pollutants. Phenols and their derivatives have been extensively used in the industrial domain, where refineries, petrochemicals, and pharmaceuticals, as well as the coal industry, make considerable contributions to phenolic contamination [1-3]. Phenol is one of the primary pollutants identified as a teratogenic and carcinogenic agent by the United States Environmental Protection Agency due to its resistance to degradation and high toxicity $[4,5]$. It is challenging to effectively remove phenol from wastewater, and various treatments such as thermal, biological, and chemical techniques have been explored. Most of these conventional technologies exhibit some limitations, such as high costs, low performance, and a long reaction time, as well as the release of harmful byproducts into the environment. Therefore, it is imperative to research alternative degradation procedures for addressing these challenges [6-8].

As an advanced oxidation process, the Fenton technology has been widely applied for the removal of non-biodegradable, persistent pollutants, such as phenol $[9,10]$. The Fenton processes involve the use of hydrogen peroxide $\left(\mathrm{H}_{2} \mathrm{O}_{2}\right)$ with an iron source $\left(\mathrm{FeSO}_{4}, \mathrm{FeCl}_{3}\right)$ to produce hydroxyl radicals $(\mathrm{OH} \cdot)$ [11-15]. However, the use of Fenton's reagent as a homogeneous catalyst exhibits several 
disadvantages. First, the reaction typically requires the continuous addition of $\mathrm{Fe}^{2+}$. Second, the process is conducted in a limited $\mathrm{pH}$ range (2.5-3.5) for the reaction to occur, and constant conditioning is required before and after the treatment $[16,17]$. Furthermore, the Fenton catalytic cycle is limited by the formation of stable $\mathrm{Fe}^{3+}$ complexes in the solution, requiring secondary treatment and additional separation steps to satisfy environmental regulations. Notably, these separation techniques lead to sharply increased operational costs [18,19].

To enhance the performance of the Fenton process, various technologies have been applied. As a photo-Fenton process, $\mathrm{UV}$ radiation can generate additional ferrous ions and $\mathrm{OH}$ radicals due to the decomposition of the photoactive iron species (Equation (1)). By using UV irradiation, $\mathrm{Fe}^{3+}$ complexes, which are formed in the Fenton process, also can be destroyed; hence, $\mathrm{Fe}^{3+}$ can participate in the catalytic cycle $[20,21]$.

$$
\mathrm{Fe}(\mathrm{OOH})^{2+}+h v \rightarrow \mathrm{Fe}^{2+}+\mathrm{OH}
$$

The limitations of homogeneous Fenton-type processes can be resolved by using heterogeneous catalysts with a low iron concentration where operation in a wide $\mathrm{pH}$ range is possible [22,23]. Moreover, the facile separation of the used catalyst and reusability are considered as the predominant advantages of the heterogeneous process.

The challenge of a heterogeneous process is mainly associated with the immobilization of iron species over different supports as a catalyst for the Fenton or photo-Fenton process, which would also enable its application without the production of $\mathrm{Fe}(\mathrm{OH})_{3}$ sludge. The other challenge is associated with the stability of the immobilized iron species, which should not exhibit leaching. By this approach, researchers have attempted to design highly stable catalysts [24]. Various materials such as bentonite, silica, activated carbon, zeolites, and clays have been investigated as supports for Fe-based catalysts [25]. Among these materials, synthetic zeolites are preferred due to their cost and unique structural properties such as a high surface area, stability, and selective adsorption ability of organic compounds. Moreover, iron-silica has been considered due to its highly porous structure, larger pore size, and high surface area [26].

Numerous studies have reported experiments and performances of Fe-based catalysts [24]. However, only a few studies have provided deep insights into the fate of catalysts after degradation. Thus, the main objective of this study is to identify an appropriate iron-containing catalyst suitable for the degradation of phenol via heterogeneous photolysis, Fenton, and photo-Fenton reactions. Three iron-incorporated crystalline and amorphous Fenton catalysts, Fe-Zeo-A, Fe-ZSM-5, and Fe-silica, were synthesized and characterized, and their performances were compared for the degradation of phenol. Moreover, a detailed spectroscopic and microscopic analysis was performed to investigate the stability and fate of catalysts using the state-of-the-art techniques such as scanning electron microscopy (SEM), transmission electron microscopy (TEM), energy dispersive $X$-ray spectroscopy (EDS), Fourier-transform infrared spectroscopy (FTIR), X-ray diffraction (XRD), X-ray photo electron spectroscopy (XPS), and electron paramagnetic resonance (EPR).

\section{Results and Discussion}

\subsection{Characterization of Catalysts}

SEM: Figure 1 shows the SEM images of Fe-ZSM-5, Fe-Zeo-A, and Fe-silica. A highly crystalline morphology was observed in the SEM image of Fe-ZSM-5, where Fe in the form of iron oxides on the surface was absent. Fe-Zeo-A cubic crystals were clearly visible in the SEM image. Some precipitate was observed on the surface due to the iron formation. A non-uniform flat surface was observed in the SEM image of Fe-Silica, which was extremely different from that observed in the case of other highly porous silica materials.

XRD: Figure 2 shows the XRD patterns of Fe-ZSM-5 (MFI type), Fe-Zeo-A (LTA type), and Fe-Silica. The powder XRD pattern of as-synthesized Fe-ZSM- 5 revealed peaks extremely similar to those observed for pure ZSM-5, which matched with JCPDS card no. 89-1421. Peaks observed at $2 \theta=$ 
$7.89^{\circ}, 8.79^{\circ}, 13.14^{\circ}, 14.71^{\circ}, 15.87^{\circ}, 23.02^{\circ}, 23.92^{\circ}, 24.41^{\circ}$, and $29.92^{\circ}$ corresponded to (101), (111), (102), (131), (022), (051), (313), (323), and (062) planes, respectively. An extremely low-intensity peak at $2 \theta=$ $33^{\circ}$ was observed in the XRD pattern of Fe-ZSM-5, corresponding to $\alpha-\mathrm{Fe}_{2} \mathrm{O}_{3}$, which confirmed the presence of an isolated extra-framework Fe species in Fe-ZSM-5. Lattice parameters $a=21.534 \AA, b$ $=20.106 \AA, c=13.690 \AA$ were obtained by considering crystals in the orthorhombic system with the space group Pnma. The XRD spectrum of Fe-Zeo-A revealed sharp peaks at $7.14^{\circ}, 10.09^{\circ}, 12.37^{\circ}, 16.07^{\circ}$, $20.32^{\circ}, 21.62^{\circ}, 23.91^{\circ}, 26.09^{\circ}, 27.07^{\circ}, 29.90^{\circ}, 30.77^{\circ}, 32.52^{\circ}$, and $34.15^{\circ}$, corresponding to (200), (220), (222), (420), (440), (442), (622), (640), (642), (644), (822), (840), and (664) planes, respectively. Fe-Zeo-A was found in the cubic system with $a=b=c=24.628 \AA$. The XRD pattern of Fe-Silica revealed a broad peak centered at $2 \theta=21.82^{\circ}$ due to a highly amorphous $\mathrm{Si}-\mathrm{O}-\mathrm{Si}$ network.
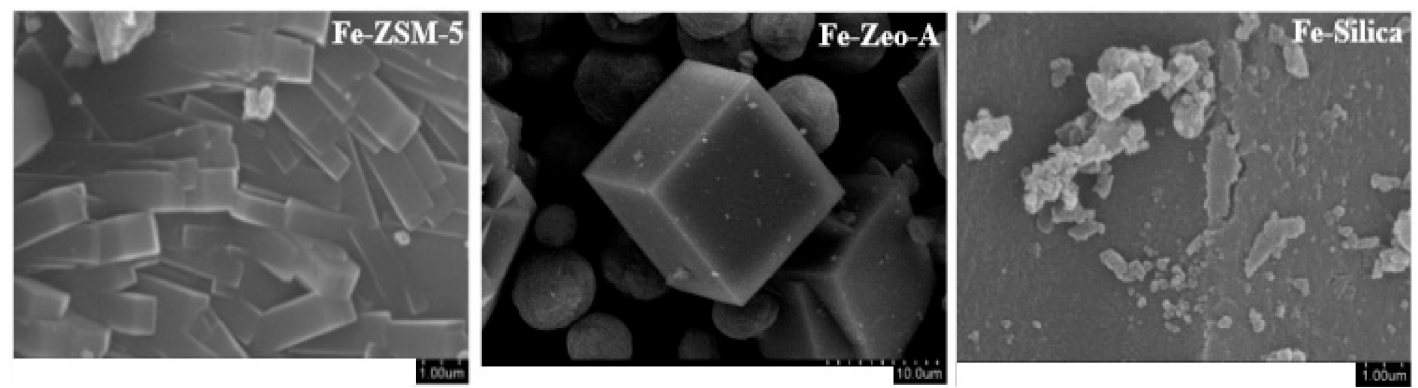

Figure 1. Scanning electron microscopy (SEM) images of Fe-ZSM-5, Fe-Zeo-A, and Fe-Silica.

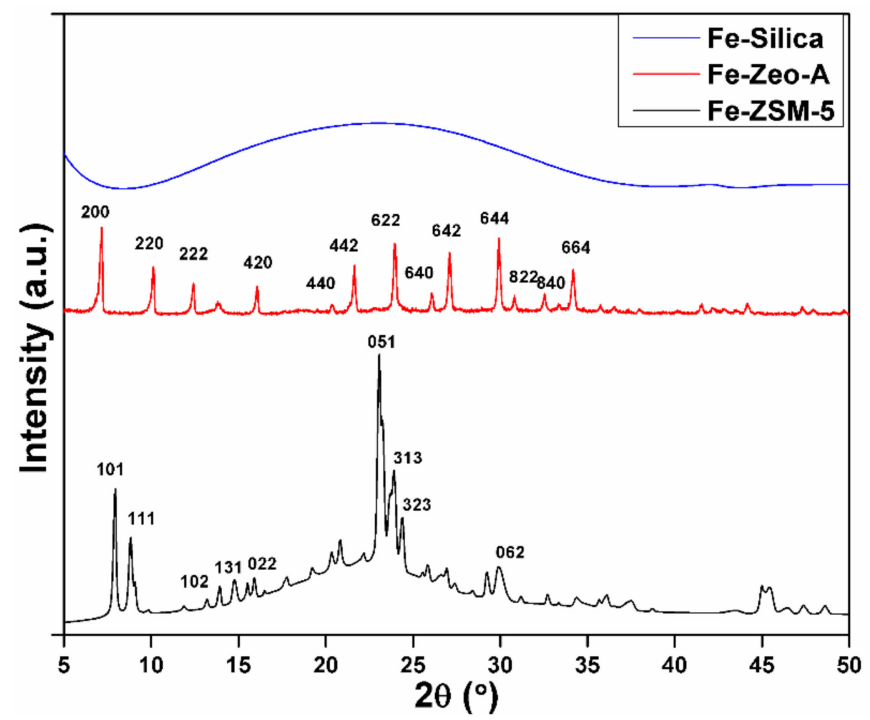

Figure 2. X-ray diffraction (XRD) spectra of Fe-ZSM-5, Fe-Zeo-A, and Fe-Silica.

HRXPS: The HRXPS Fe 2p spectra of Fe-loaded catalysts revealed peaks at 711.59-711.89 eV and $725.02-725.62 \mathrm{eV}$ for $\mathrm{Fe} 2 \mathrm{p}_{3 / 2}$ and $\mathrm{Fe} 2 \mathrm{p}_{1 / 2}$, respectively, confirming the presence of $\mathrm{Fe}^{3+}$ species [27] (Figure 3). The deconvoluted HRXPS O 1s spectrum of Fe-ZSM-5 revealed four bands at $530.18 \mathrm{eV}$, $531.34 \mathrm{eV}, 531.90 \mathrm{eV}$, and $533.23 \mathrm{eV}$, corresponding to $\mathrm{Al}-\mathrm{O}, \mathrm{O}-\mathrm{H}, \mathrm{Si}-\mathrm{O}$, and physisorbed water molecules, respectively (Figure 3). Similar peaks were recorded for Fe-Zeo-A. The HRXPS O 1s spectrum of Fe-Silica revealed peaks at $529.06 \mathrm{eV}, 532.25 \mathrm{eV}, 532.89 \mathrm{eV}$, and $535.64 \mathrm{eV}$, corresponding to $\mathrm{Fe}-\mathrm{O}, \mathrm{Si}-\mathrm{O}$, $\mathrm{O}-\mathrm{H}$, and physisorbed water molecules, respectively. Table $\mathrm{S} 1$ summarizes the elemental analysis. 

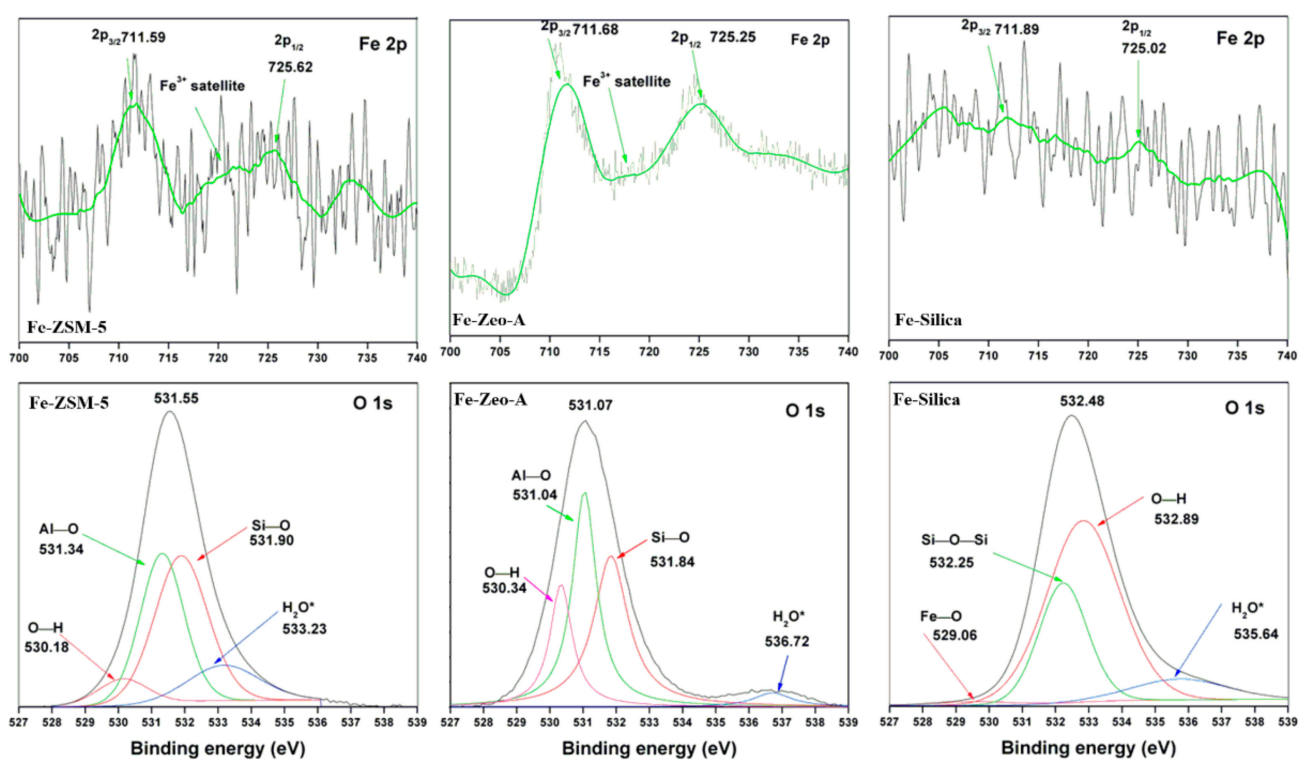

Figure 3. HRXPS Fe 2p and deconvoluted HRXPS O 1s spectra of Fe-ZSM-5, Fe-Zeo-A, and Fe-Silica.

EPR: Figure 4 shows the EPR spectra of Fe-ZSM-5, Fe-Zeo-A, and Fe-Silica recorded at $77 \mathrm{~K}$. The EPR spectrum of Fe-ZSM-5 revealed the presence of $\mathrm{Fe}^{3+}$. The signals observed at $g=1.987$ and $g=4.393$ are typical for the Fe species in Fe-ZSM-5 [28]. The high intensity and narrower signal at $g=1.987$ corresponded either to isolated $\mathrm{Fe}^{3+}$ in high symmetry or to $\mathrm{Fe}_{\mathrm{x}} \mathrm{O}_{\mathrm{y}}$ clusters and $\mathrm{Fe}_{2} \mathrm{O}_{3}$ nanoparticles. Moreover, the high resolution of this signal was indicative of the uniform distribution of $\mathrm{Fe}_{\mathrm{x}} \mathrm{O}_{\mathrm{y}}$ clusters in the Fe-ZSM- 5 catalysts. The signal at $g=4.393$ corresponded to $\mathrm{Fe}^{3+}$ incorporated in a tetrahedral coordination environment or isolated ions in extra-framework positions [28]. The lower intensity and larger linewidth revealed that framework $\mathrm{Fe}^{3+}$ was less abundant in the catalysts. The EPR spectrum of Fe-Zeo-A revealed a broad, high-intensity signal at $g=2.140$, indicating that extra-framework Fe exists as $\mathrm{Fe}_{2} \mathrm{O}_{3}$ nanoparticles. An extremely low-intensity signal observed at $g$ $>3$ corresponded to isolated ions in extra-framework positions. For Fe-Silica, only one signal at $g=$ 1.989 was observed, showing only one coordination environment of $\mathrm{Fe}$, that is, $\mathrm{Fe}_{2} \mathrm{O}_{3}$ nanoparticles embedded in the silica network [29]. Supplementary Section 2 summarizes TEM, Raman, and FTIR analyses. the Brunauer-Emmett-Teller (BET)data have been shown in Table S2.

\subsection{Phenol Removal Performance}

Heterogeneous photolysis: Figure 5 shows the effect of UV irradiation on the phenol degradation performance of Fe-based catalysts. The observed removal efficiencies can be attributed to the formation of $\mathrm{OH}$ radicals via the photocatalytic cleavage of hydroxyl groups on the catalyst surface [15]. Owing to the insufficient concentration of the radicals formed, the photocatalytic degradation of a small fraction of phenol was possible. The phenol degradation performance decreased in the order of Fe-Silica $>$ Fe-Zeo-A > Fe-ZSM-5, which was in agreement with the density of hydroxyl groups present in the catalysts. From FTIR spectra, the hydroxyl density of Fe-Silica was greater than those of Fe-Zeo-A and Fe-ZSM-5, which generated OH radicals under UV irradiation. Moreover, the UV excitation of Fe species followed by phenol degradation was another possible mechanism that contributed to the process [30]. The iron content of Fe-ZSM-5 was greater than that of Fe-Zeo-A; hence, Fe-ZSM-5 exhibits a higher photocatalytic activity. As the phenol degradation performance was found to be significantly low, only UV irradiation was an ineffective process for phenol removal.

Adsorption: Figure S6 shows the adsorption of phenol on Fe-ZSM-5, Fe-Zeo-A, and Fe-Silica. Less than $10 \%$ of the phenol was adsorbed on all catalysts after $24 \mathrm{~h}$, suggesting that adsorption is not a viable method for the removal of phenol and that catalytic degradation is mandatory. 
Heterogeneous Fenton reaction: Figure 6 shows the effect of $\mathrm{H}_{2} \mathrm{O}_{2}$ on the phenol degradation performance of catalysts. As opposed to UV irradiation, $\mathrm{H}_{2} \mathrm{O}_{2}$ was found to be effective for the degradation of phenol. In the initial phase, higher phenol degradation rates were achieved due to the abundance of the generated hydroxyl radicals due to redox reactions. However, as time elapsed, slower kinetics were related to the reduced phenol concentration of the solution phase. The catalytic activity of Fe-ZSM-5 was greater than those of Fe-Silica and Fe-Zeo-A. As the formation of hydroxyl radicals is a function of the iron concentration in the redox reactions, Fe-ZSM-5 (1.33 wt.\%) with a higher iron content dominated over Fe-Zeo-A (1.02 wt.\%) and Fe-Silica (0.72 wt.\%).
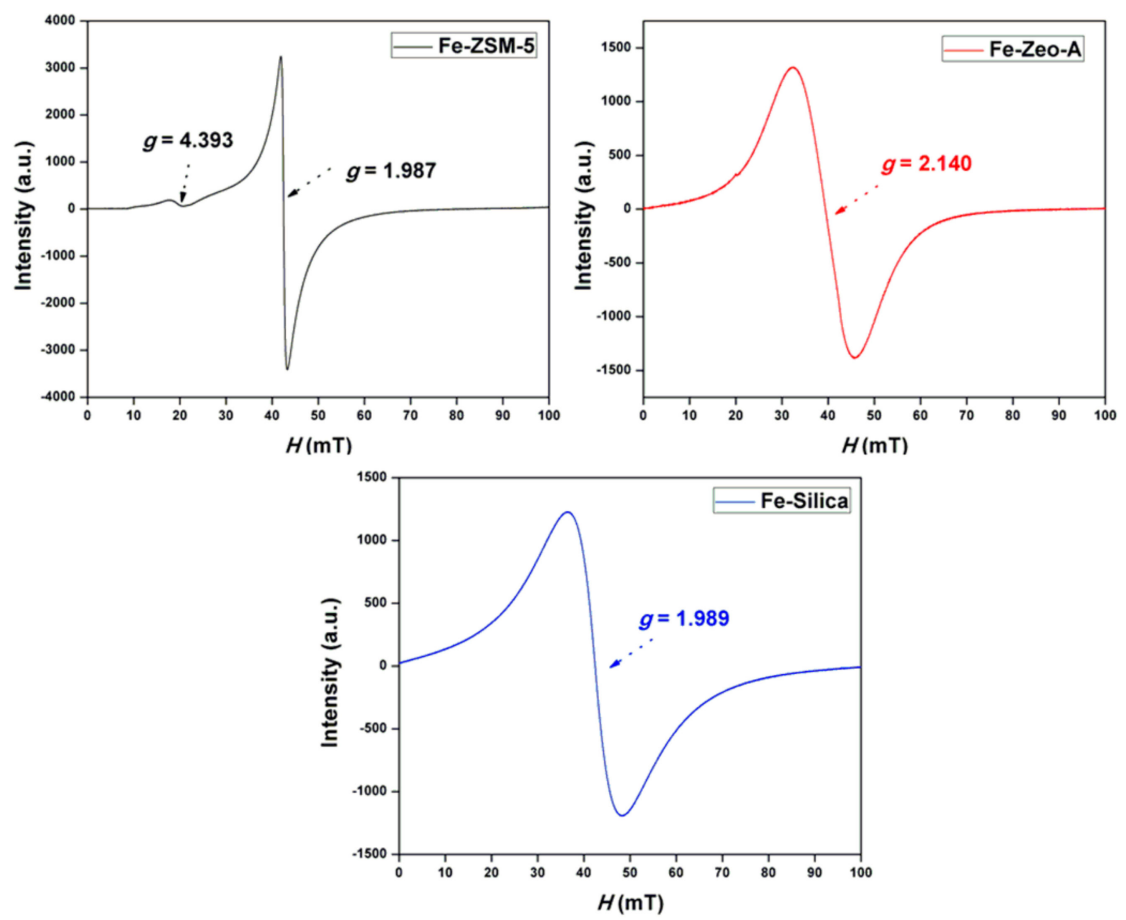

Figure 4. Electron paramagnetic resonance (EPR) spectra of Fe-ZSM-5, Fe-Zeo-A, and Fe-Silica at $77 \mathrm{~K}$.

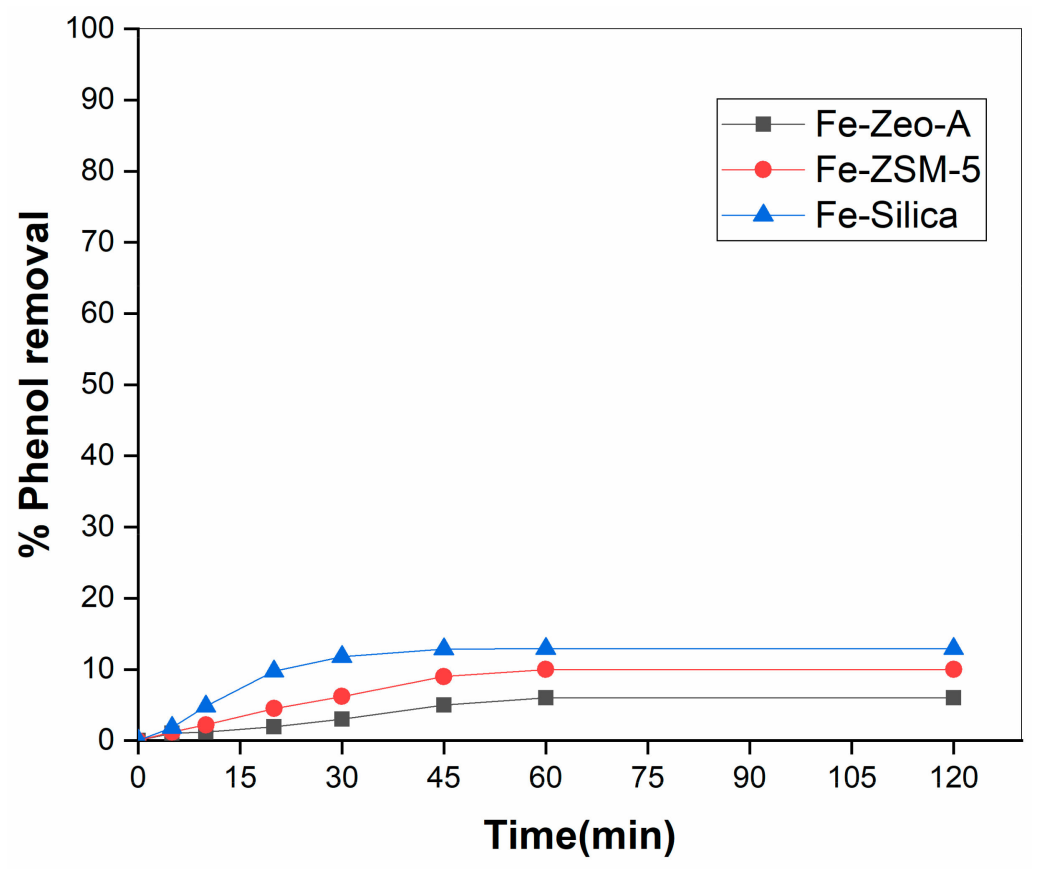

Figure 5. Heterogeneous photolytic degradation of phenol. 


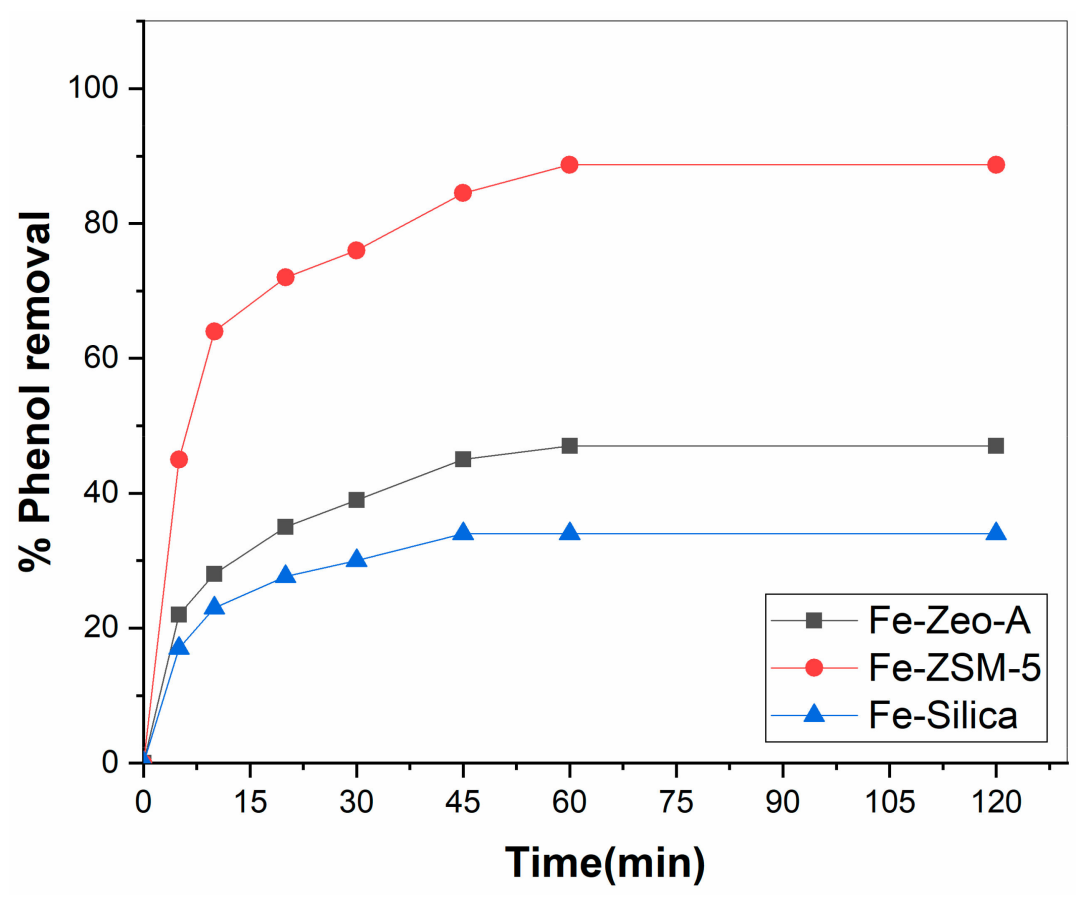

Figure 6. Heterogeneous Fenton degradation of phenol.

Heterogeneous Photo-Fenton reaction: Figure 7 shows the effect of $\mathrm{UV}+\mathrm{H}_{2} \mathrm{O}_{2}$ on the degradation of phenol. In this process, the phenol removal efficiency increased in comparison to those observed for photolysis and the Fenton process. This increase was attributed to the synergistic effect of UV irradiation and $\mathrm{H}_{2} \mathrm{O}_{2}$ toward $\mathrm{OH}$ radical formation [30]. The photo-Fenton process led to the enhanced density of the radical species via the photolytic cleavage of hydroxyl groups, UV-induced active Fe species, and the conventional Fenton process. An active species trapping experiment was conducted for hydroxyl radicals using tert-butanol as the scavenger of hydroxyl radicals. Owing to the presence of the scavenger in the aqueous phase, the phenol removal performance over Fe-based catalysts decreased, indicating that hydroxyl radicals participate in the degradation of phenol (Figure 7).

(a)

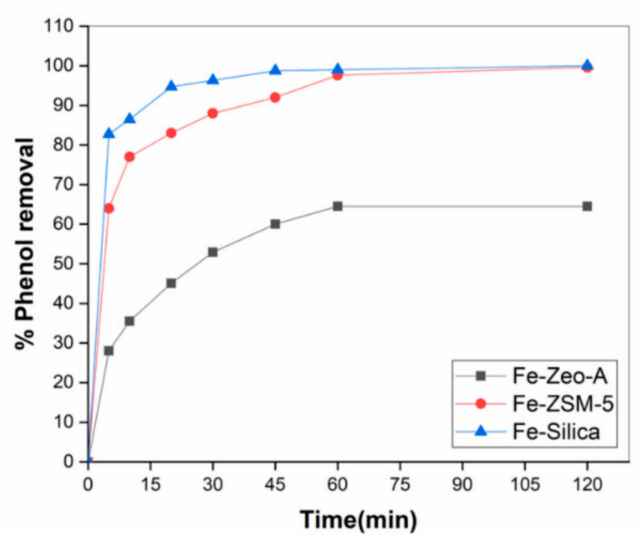

(b)

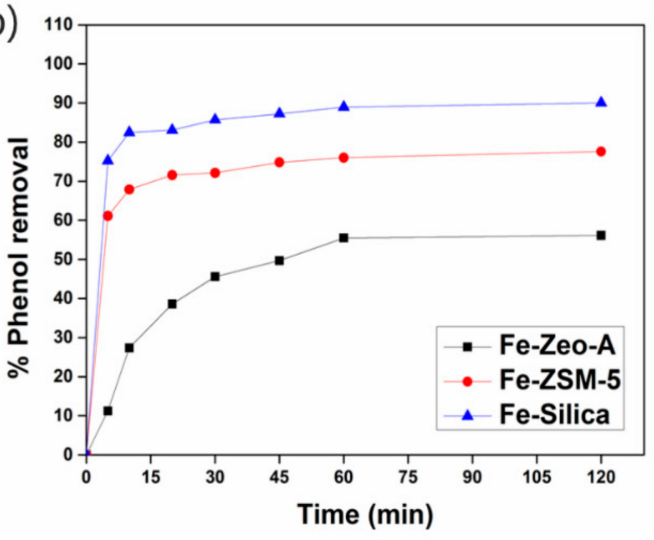

Figure 7. Heterogeneous photo-Fenton degradation of phenol in the (a) absence and (b) presence of tert-butanol $(1.5 \mathrm{~mL})$.

Moreover, the least iron deactivation (due to the complexation of Fe with acidic byproducts) was expected in the photo-Fenton process. Clearly, the phenol removal abilities of Fe-Silica and Fe-ZSM-5 were extremely greater than that of Fe-Zeo-A. Even though the concentration of Fe was low in Fe-Silica, the process was significantly more rapid, with a phenol removal of $\sim 99 \%$. TEM analysis (vide infra) clearly revealed that the iron loss increases in the order of Fe-ZSM-5 $(6 \%)<$ Fe-Zeo-A $(10 \%)<$ Fe-Silica 
(14\%). Amorphous Fe-silica exhibited significant iron loss due to a highly open catalyst structure, where iron was loosely incorporated as an oxide. The iron leached in the solution phase led to the partial involvement of the homogeneous reaction along with the heterogeneous reaction $[24,26]$. As the homogeneous process is more rapid than the heterogeneous process, Fe-Silica exhibited rapid phenol degradation compared to the others.

On the contrary, crystalline Fe-ZSM- 5 exhibited an iron loss of $6 \%$ due to the distribution of iron as oxides in the nanocrystallite form in the ordered pores or as framework iron in the bonded form. Thus, in the case of Fe-ZSM-5, phenol degradation occurs via the heterogeneous photo-Fenton reaction. Fe-Zeo-A exhibited a 10\% decrease in the iron content after phenol degradation, and the kinetics and performance remained considerably low due to the formation and deposition of iron-byproduct complexes (as observed in the SEM image), which led to the non-availability of iron in the later stages of the process. Furthermore, the increased solution $\mathrm{pH}$, due to the release of hydroxide ions, led to the formation of iron hydroxides with the leached iron, thereby decreasing the concentration of available iron for the process. In addition, the decomposition of $\mathrm{H}_{2} \mathrm{O}_{2}$ to $\mathrm{H}_{2} \mathrm{O}$ and $\mathrm{O}_{2}$ at high $\mathrm{pH}$ disfavored the photo-Fenton process.

\subsection{Fate of Catalysts}

SEM: Figure 8 shows the morphology and structure of the used Fe-ZSM-5, Fe-Zeo-A, and Fe-Silica after the degradation of phenol. In the SEM images of Fe-ZSM-5, the crystal structure of catalysts clearly remained intact. However, in the SEM image of Fe-Zeo-A, the cubic crystal structure deteriorated, which indicates the lower structural stability of Fe-Zeo-A. In the SEM image of Fe-Silica, no changes after phenol removal were observed.

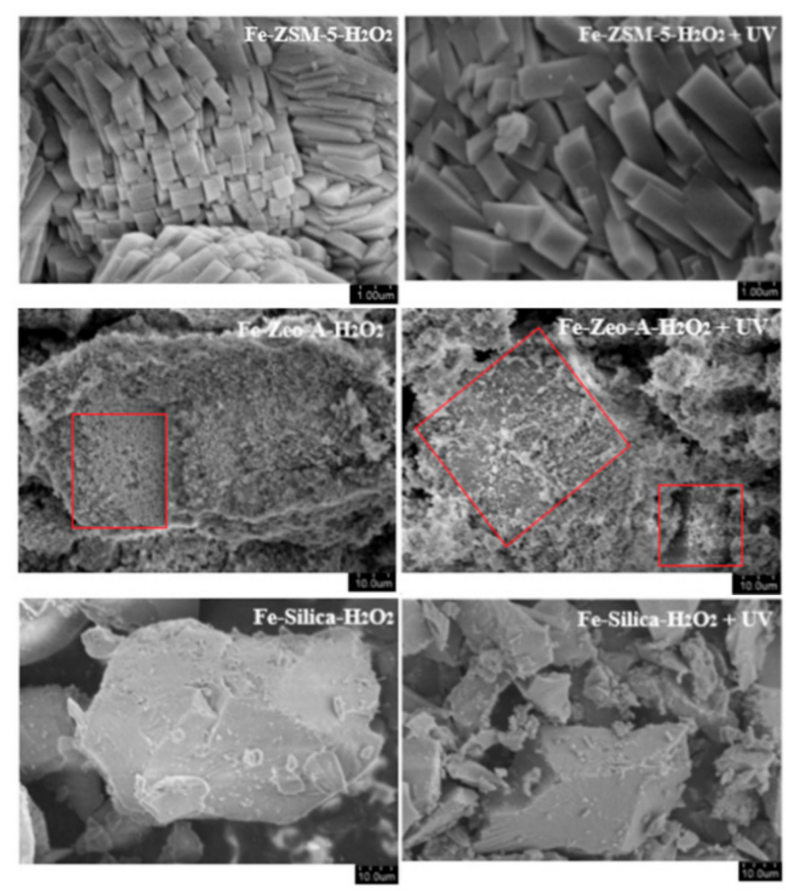

Figure 8. SEM images of Fe-ZSM-5, Fe-Zeo-A, and Fe-Silica after phenol degradation with $\mathrm{H}_{2} \mathrm{O}_{2}$ and with $\mathrm{H}_{2} \mathrm{O}_{2}+\mathrm{UV}$.

TEM: Figure 9 shows the TEM images of Fe-ZSM-5, Fe-Zeo-A, and Fe-Silica after phenol degradation with $\mathrm{H}_{2} \mathrm{O}_{2}+\mathrm{UV}$. The morphology of Fe-ZSM-5 remained intact even after the catalytic degradation of phenol. On the contrary, a highly distorted morphology was observed for Fe-Zeo-A. EDX analysis revealed that the Fe loss for Fe-ZSM-5, Fe-Zeo-A, Fe-Silica was 6\%, 10\%, and 14\%, respectively. 


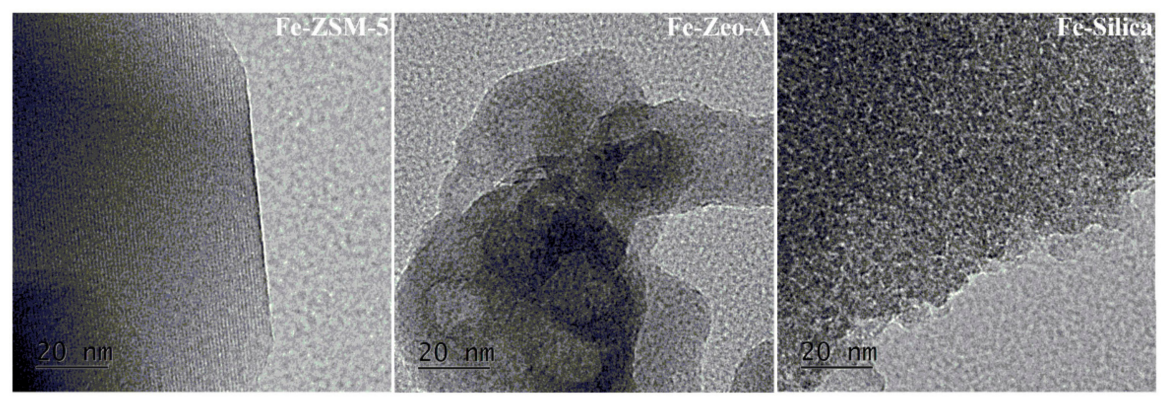

Figure 9. Transmission electron microscopy (TEM) images of Fe-ZSM-5, Fe-Zeo-A, and Fe-Silica after phenol degradation with $\mathrm{H}_{2} \mathrm{O}_{2}+\mathrm{UV}$.

XRD: The crystallographic structures of Fe-ZSM-5 after phenol adsorption and degradation revealed spectra extremely similar to those of pristine catalysts with slight non-periodic shifts in the $2 \theta$ values (Figure 10). The calculated lattice parameters were found to increase after phenol degradation (Table S3). These distortions of the unit cell may be related to the accumulation of byproducts in the structure. Moreover, the application of $\mathrm{UV}+\mathrm{H}_{2} \mathrm{O}_{2}$ was more effective due to the lower unit cell volume than that observed by the application of $\mathrm{H}_{2} \mathrm{O}_{2}$ alone, probably due to a higher degree of oxidation, thereby lowering the proportion of byproducts. For Fe-Zeo-A, some degree of amorphicity, with the disappearance of the peak at $2 \theta=20.32^{\circ}$, was observed in the XRD spectra, indicative of the poor structural stability of Fe-Zeo-A. In addition, structural variations were observed in the SEM images (vide supra). In the XRD patterns of Fe-Silica, significant irregular shifts in the peak at $2 \theta=$ $23.01^{\circ}$ (pristine) to 22.08 (Fe-Silica- $\mathrm{H}_{2} \mathrm{O}_{2}$ ) and 24.85 (Fe-Silica- $\mathrm{H}_{2} \mathrm{O}_{2}+\mathrm{UV}$ ), in addition to changes in the features strongly revealed the restructuring of the silica network.

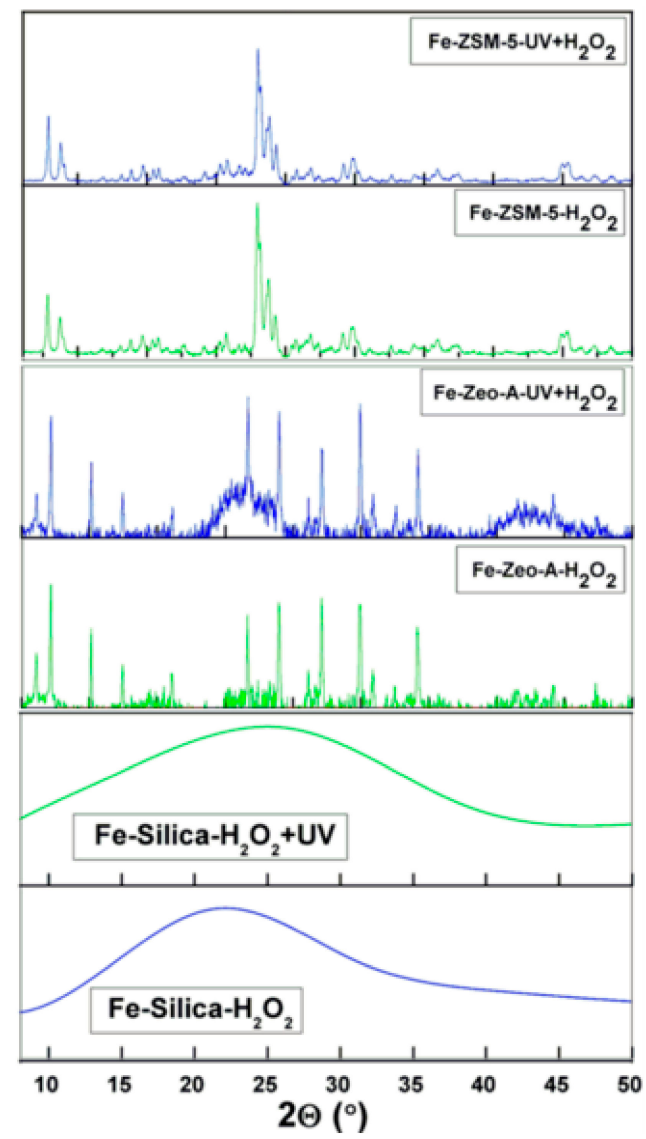

Figure 10. XRD spectra of Fe-ZSM-5, Fe-Zeo-A, and Fe-Silica after phenol degradation with $\mathrm{H}_{2} \mathrm{O}_{2}$ and $\mathrm{H}_{2} \mathrm{O}_{2}+\mathrm{UV}$. 
FTIR: Figure 11 shows the FTIR spectra of pristine and used Fe-ZSM- 5 catalysts. After phenol degradation, the relative intensity of Fe-ZSM-5 decreased significantly. The intensity of the band at $3200-3800 \mathrm{~cm}^{-1}$ (corresponding to hydroxyl groups) decreased with the catalytic process, due to the consumption of these hydroxyl groups in the photo-Fenton and Fenton processes. The $\mathrm{I}_{550} / \mathrm{I}_{450}$ index calculated for Fe-ZSM-5 decreased from 0.817 ( 100\% crystallinity) to 0.768 ( $\sim 96 \%$ crystallinity) for Fe-ZSM-5- $\mathrm{H}_{2} \mathrm{O}_{2}+\mathrm{UV}$. The stability of the catalyst crystals in the Fenton process ( $100 \%$ crystallinity) were greater than that in the photo-Fenton process. Thus, an interplay between the performance and stability of the catalyst is present. Similar effects were observed for Fe-Zeo-A and Fe-Silica, where the intensity hydroxyl groups were found to decrease after phenol degradation (Figure 11).

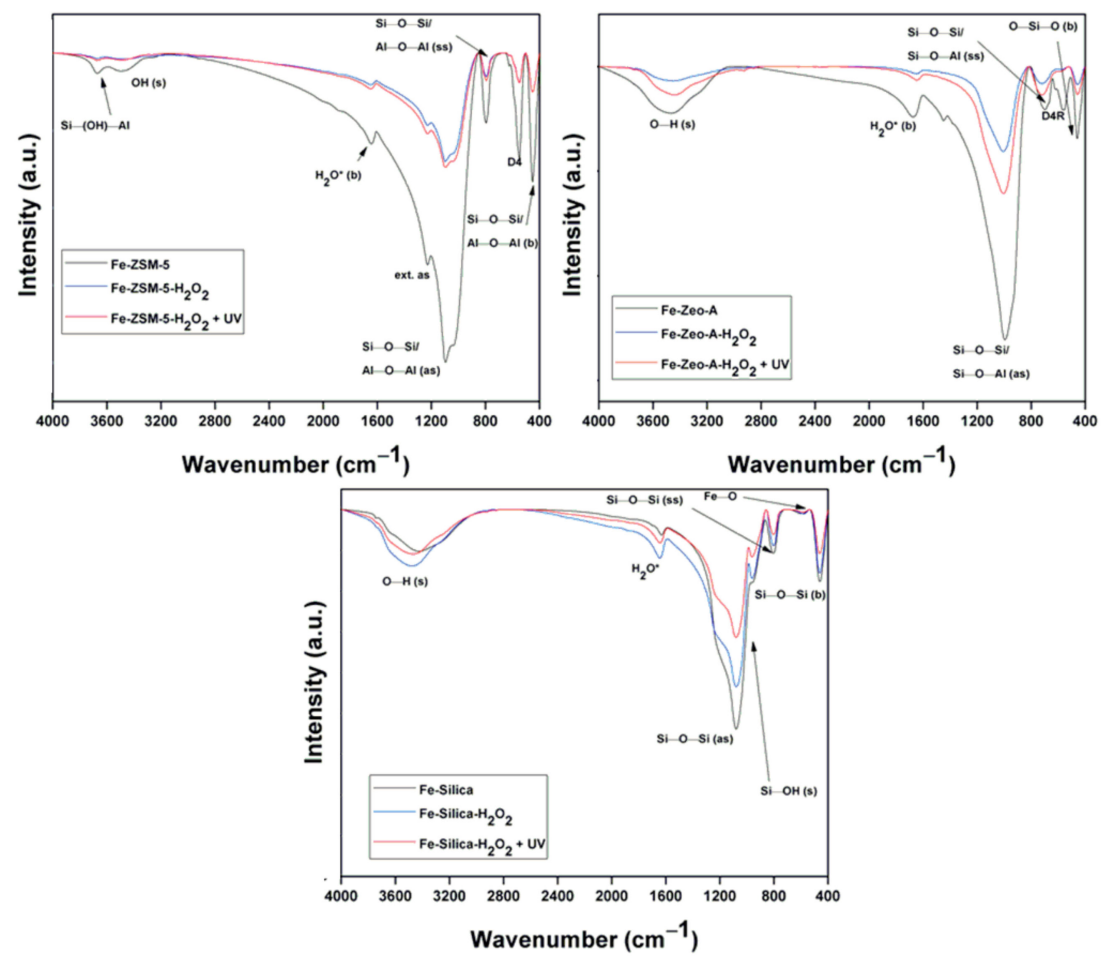

Figure 11. FTIR spectra of Fe-ZSM-5, Fe-Zeo-A, and Fe-Silica after phenol degradation with $\mathrm{H}_{2} \mathrm{O}_{2}$ and $\mathrm{H}_{2} \mathrm{O}_{2}+\mathrm{UV}$.

XPS: The HRXPS Fe 2p spectra of the used catalysts exhibited a slight shift in the peaks in addition to the diminished intensity (Figure 12). Thus, a loss of Fe from the catalyst as well as the change in the structure are significant after phenol degradation. In the deconvoluted HRXPS O 1s spectra of the used catalysts, the area under the $\mathrm{O}-\mathrm{H}$ peak decreased after use due to the consumption of these hydroxyl groups as hydroxyl radicals (under the effect of $\mathrm{UV}$ and $\mathrm{H}_{2} \mathrm{O}_{2}$ ). Table $\mathrm{S} 4$ summarizes the elemental analysis. 

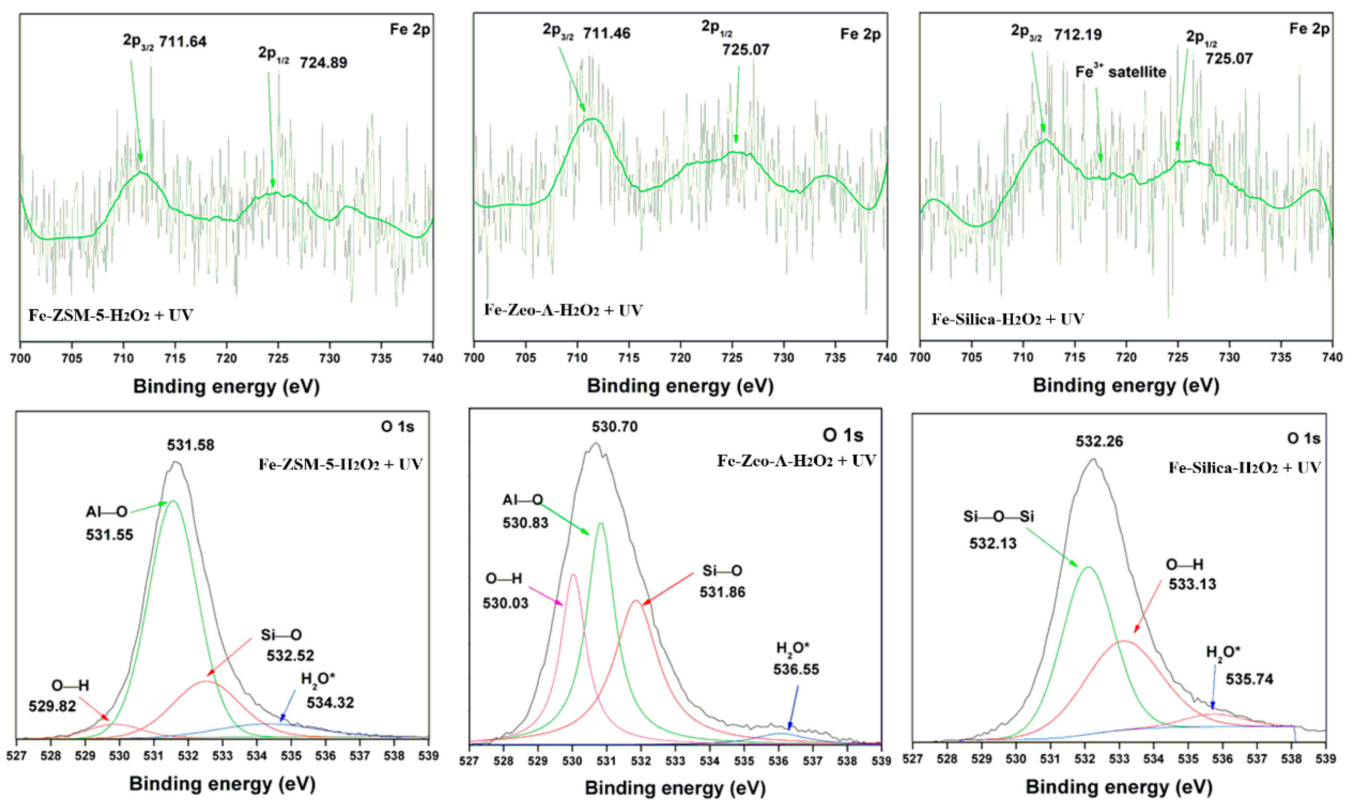

Figure 12. HRXPS Fe 2p and deconvoluted O 1 s spectra of Fe-ZSM-5, Fe-Zeo-A, and Fe-Silica after phenol degradation with $\mathrm{H}_{2} \mathrm{O}_{2}+\mathrm{UV}$.

EPR: Figure 13 shows the EPR spectra of Fe-ZSM-5, Fe-Zeo-A, and Fe-Silica after phenol degradation with $\mathrm{UV}+\mathrm{H}_{2} \mathrm{O}_{2}$. The intensity of the signal at $g \sim 2$ for all the three catalysts decreased after phenol degradation, due to the loss of iron from the catalysts. As the signal at $g \sim 2$ corresponded to $\mathrm{Fe}_{\mathrm{x}} \mathrm{O}_{\mathrm{y}}$ clusters or $\mathrm{Fe}_{2} \mathrm{O}_{3}$ nanoparticles, slight leaching of this form of iron is probable. Based on the signal intensity, Fe-Silica exhibited the maximum Fe loss. The intensity of the signal at $g \sim 4.2-4.4$ for Fe-ZSM-5 and Fe-Zeo-A remained the same, indicative of the higher stability of framework iron. Based on the experimental and spectroscopic analysis, Figure 14 shows a proposed mechanism for the degradation of phenol.
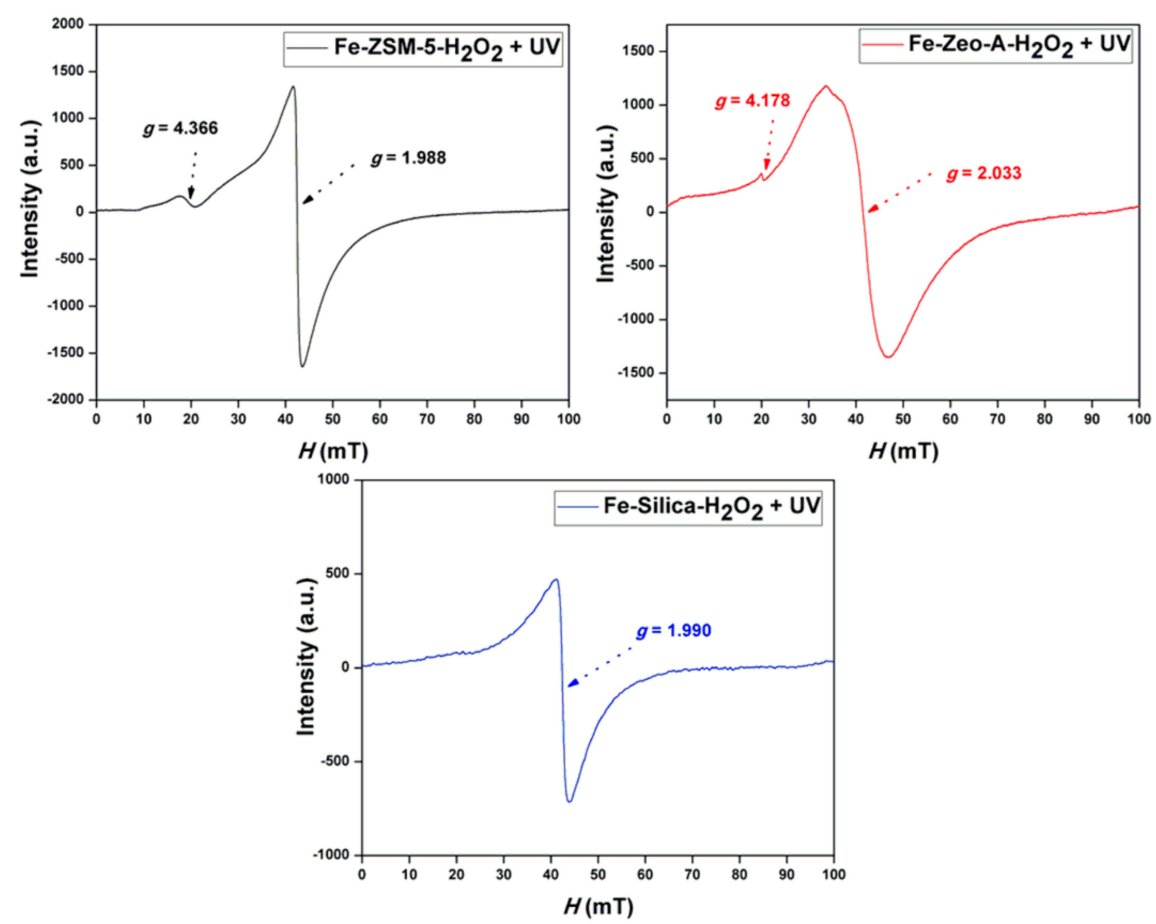

Figure 13. EPR spectra of Fe-ZSM-5, Fe-Zeo-A, and Fe-Silica after phenol degradation with UV $+\mathrm{H}_{2} \mathrm{O}_{2}$. 

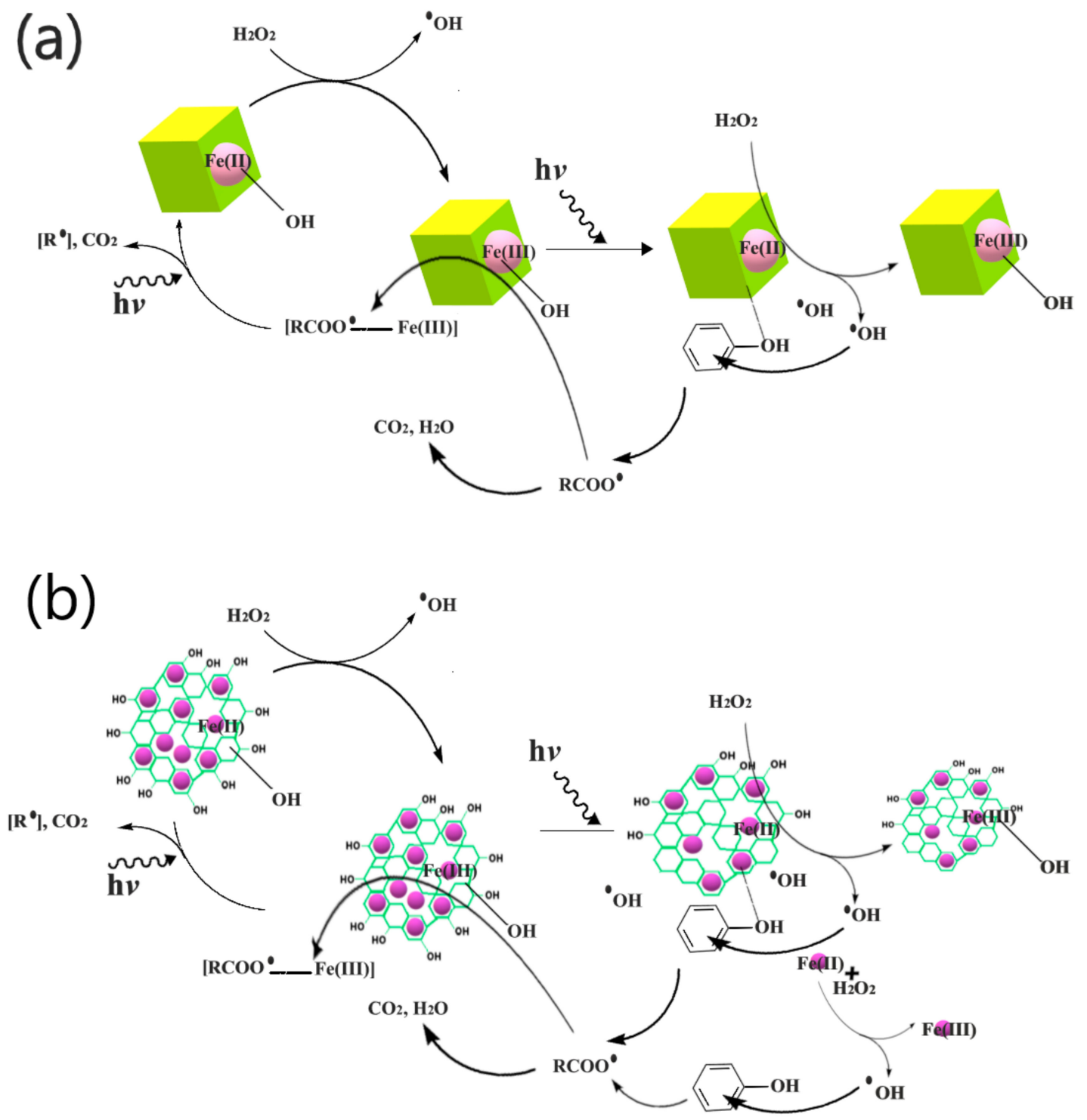

Figure 14. Possible mechanism for the catalytic degradation of phenol on Fe-containing (a) zeolites and (b) silica.

\subsection{Reusability of Catalysts}

The reusability of Fe-incorporated catalysts was examined for three cycles to investigate the applicability of these catalysts for phenol degradation (Figure 15). Clearly, the degradation performance of phenol over Fe-ZSM-5 decreased slightly, but over Fe-Zeo-A, a significant loss in the performance was observed (phenol). The decrease in the phenol removal efficiency was directly related to the Fe loss in the successive catalytic cycle, and for the same reason, Fe-ZSM-5 exhibited better performance in multiple runs. 


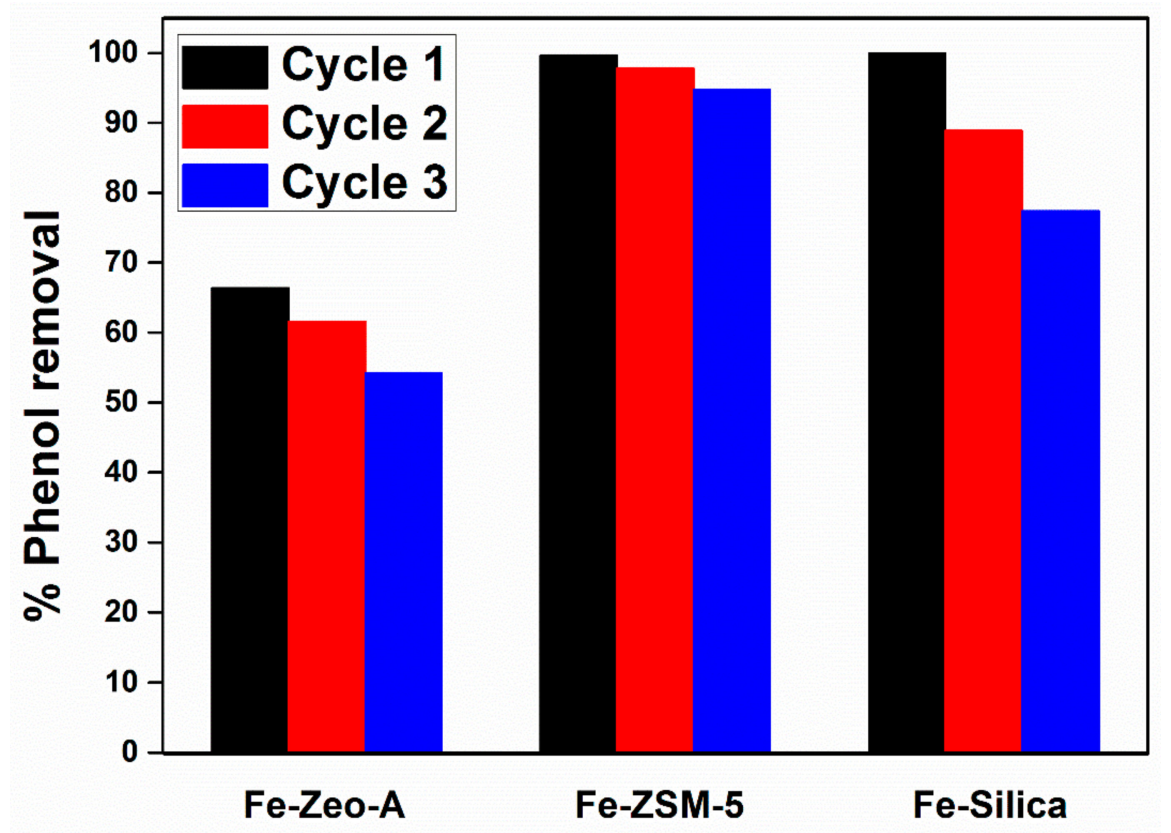

Figure 15. Reusability of Fe-based catalysts for phenol degradation.

\section{Materials and Methods}

\subsection{Chemicals}

Phenol, ACS (<99\%) was purchased from Alfa Aesar, United States. Hydrogen peroxide $\left(\mathrm{H}_{2} \mathrm{O}_{2}\right.$, $30 \mathrm{wt} \%$ aqueous), sodium silicate $\left(\mathrm{Na}_{2} \mathrm{SiO}_{3}\right)$, and sodium aluminate $\left(\mathrm{NaAlO}_{2}\right)$ were purchased from Junsei Chemical Co., Ltd., Japan. Silica sol $\left(\mathrm{SiO}_{2} 40 \%\right)$, tetrapropylammonium hydroxide (TPAOH), ammonium iron citrate (AIC), a cetyltrimethylammonium chloride (CTAC) solution (25 wt.\%), tert-butanol (98\%), and iron(II) acetate (95\%) were purchased from Sigma-Aldrich, Germany. Tetraethyl orthosilicate (95\%, TEOS) was purchased from Samchun Company, South Korea. Sodium hydroxide $(\mathrm{NaOH})$ was purchased from Kanto Chemical Co., Inc., Japan. Deionized water was used in all the synthesis and experiments.

\subsection{Synthesis of Catalysts}

Crystalline Fe-Zeolite A: Fe-Zeolite-A was synthesized in a hydrothermal reactor by the sol-gel method. The molar ratio of the $\mathrm{Na}_{2} \mathrm{O}: \mathrm{SiO}_{2}: \mathrm{Al}_{2} \mathrm{O}_{3}: \mathrm{Fe}: \mathrm{H}_{2} \mathrm{O}$ mixture was selected to be 3.1:2.0:1.0:0.1:400.9. Synthesis details are provided in Supplementary Section 1 [31]. The sample was labeled as Fe-Zeo-A.

Crystalline Fe-ZSM-5: Fe-ZSM-5 was prepared from $40 \% \mathrm{SiO}_{2}, \mathrm{NaOH}, \mathrm{NaAlO}_{2}$, and TPAOH (as a structure-directing agent) by the hydrothermal method. The synthesis mixture comprises the following molar ratio of $6.2 \mathrm{Na}_{2} \mathrm{O}: 50.4 \mathrm{SiO}_{2}: 1.0 \mathrm{Al}_{2} \mathrm{O}_{3}: 1.5$ TPAOH:1.0 $\mathrm{Fe}_{2} \mathrm{O}_{3}: 1248.3 \mathrm{H}_{2} \mathrm{O}$. Supplementary S1 shows the details of the synthesis [32]. The sample was coded as Fe-ZSM-5.

Amorphous Fe-containing silica ( $\mathrm{Fe}_{2} \mathrm{O}_{3}$-Silica): The sol-gel method was used for synthesizing this catalyst. First, $0.15 \mathrm{~g}$ of iron acetate was dissolved in $60 \mathrm{~mL}$ of the CTAC solution, followed by the addition of $60 \mathrm{~mL}$ of TEOS to the mixture. Second, the mixture was transferred to an incubator for aging at $25^{\circ} \mathrm{C}$ and stirring at $200 \mathrm{rpm}$ for $24 \mathrm{~h}$. The solid material was subjected to calcination at 550 ${ }^{\circ} \mathrm{C}$ for $6 \mathrm{~h}$. The synthesis mixture comprises the following molar ratio of 1.0 TEOS:0.7 CTAC:0.003 iron acetate. The sample was coded as Fe-Silica.

\subsection{Instruments}

The surface morphology of the prepared materials was monitored using SEM, Hitachi S-4800, Hitachi, Tokyo, Japan. Dried samples were finely ground and coated with a gold-platinum alloy 
by ion sputtering with the help of an E-1045 Hitachi ion sputter. TEM images were recorded with a field-emission TEM instrument (FE-TEM, JEM-2010 Michigan, USA). Thermogravimetric analysis (TGA) was performed using a thermogravimetric analyzer (TGA 8000, Perkin Elmer, Waltham, MA, USA). The BET method was used to calculate the total surface area of the prepared materials. $\mathrm{N}_{2}$ adsorption was performed at $77 \mathrm{~K}$ on a Gemini series Micromeritics 2360 instrument (USA). Samples were previously degassed at $473 \mathrm{~K}$ for $2 \mathrm{~h}$ using a Micromeritics Flow Prep 060. A Perkin Elmer FTIR spectrometer (Waltham, Massachusetts, USA) was used with KBR pellets. The sample spectra were recorded on a single-beam spectrometer with 60 added scans at a resolution of $0.02 \mathrm{~m}^{-1}$. Raman spectra were recorded on a Raman micro spectrometer (XploRA, Horiba Jobin Yvon, Horiba-Scientific, France) equipped with a 100× objective lens with a numerical aperture of 0.9 (Olympus, Tokyo, Japan). Raman measurements were performed using a diode laser $(\lambda \sim 785 \mathrm{~nm})$, and Raman signals were detected using a charge coupled device detector. A Rigaku D/Max-2500 X-ray diffractometer (Tokyo, Japan) with $\mathrm{CuKa}$ radiation and a $\mathrm{Ni}$ filter was utilized to examine the crystallinity of the synthesized materials. Diffraction patterns were recorded between the $2 \theta$ diffraction patterns at $5^{\circ}-50^{\circ}$ with a scanning speed of $3^{\circ} \mathrm{min}^{-1}$. A Kratos Axis Ultra XPS instrument (Massachusetts, Uk). with a monochromatic Al Ka X-ray source was used for XPS analysis, which was performed at a low pressure of $1.33 \times 10^{-7}$ $\mathrm{Pa}$. The material composition was determined on the basis of the areas of Si 2p, Al 2p, Fe 2p, and $\mathrm{O}$ 1s photoelectron peaks. EPR measurement was carried on a JEOL JES-FE1C X-band spectrometer. The phenol concentration was measured using a double-beam UV-Vis Lambda 365 Perkin Elmer instrument at $270 \mathrm{~nm}$.

\subsection{Catalytic Activity Test}

Preliminary tests were carried out for the comparison of adsorption, photolysis, heterogeneous Fenton, and heterogeneous photo-Fenton processes. The adsorption, Fenton, and photo-Fenton process experiments were conducted using $0.2 \mathrm{~g} \mathrm{~L}^{-1}$ of catalyst, $10 \mathrm{mg} \mathrm{L}^{-1}$ of phenol, and $2 \% \mathrm{H}_{2} \mathrm{O}_{2}$ at $25^{\circ} \mathrm{C}$ for $2 \mathrm{~h}$. The $\mathrm{pH}$ was adjusted to 4.0 using $\mathrm{H}_{2} \mathrm{SO}_{4}$. Heterogeneous photo-Fenton reactions were carried out in a rectangular reactor with four UV lamps installed at the top and bottom (19 W, UV-C, $I_{\max }$ $254 \mathrm{~nm}$ ). The reactor contained a cylindrical quartz cell with a capacity of $250 \mathrm{~mL}$. The reaction was initiated by the insertion of the cell under a UV lamp. After irradiation, samples were taken at different time intervals using a syringe filter (Hyundai micro, Korea, model: SN25P045NS) with a pore size of $0.45 \mu \mathrm{m}$. The reactor was placed in the dark to avoid any external irradiation. The Fenton reaction was performed in the same reactor, without UV irradiation. The scavenger study was conducted under the same conditions with the addition of $1.5 \mathrm{~mL}$ of tert-butanol in the aqueous phase. For the reusability study, the spent catalysts were washed thrice with distilled water and loaded again, where all experimental parameters were the same as those utilized for the photo-Fenton process.

\section{Conclusions}

The photolytic cleavage of hydroxyl groups, photo-active Fe species, and generation of radicals by the heterogeneous photo-Fenton process contribute to the degradation of phenol in varying proportions for the three Fe-based catalysts. The presence of an isolated iron species (e.g., in amorphous Fe-silica) is found to be more sensitive to be leached out. This is confirmed by the amount of Fe(III) leached from the solution, leading to a slight homogenous reaction induced by surface-leached iron, in addition to the heterogeneous reaction. Subsequently, this results in more rapid phenol oxidation compared to the other two catalysts. On the other hand, the highly crystalline Fe-ZSM-5 exhibits limited iron leaching, due to the iron bonded to the framework or iron as a nanocrystalline oxide. Hence, the system proceeds via a heterogeneous reaction with outstanding stability. Although Fe-Zeo-A is crystalline, iron is present as oxides on the surface, which limits the stability of the catalyst. Typically, compared to amorphous materials, crystalline samples exhibit a slower degradation rate. However, crystalline samples are more stable, and their catalytic action is dominated by the heterogeneous reaction. Therefore, the 
overall analysis result revealed that crystalline Fe-ZSM- 5 is a promising catalyst for the heterogeneous photo-Fenton processes, which was confirmed by XRD, EPR, and XPS analyses.

Supplementary Materials: The following are available online at http:/www.mdpi.com/2073-4344/9/10/859/s1.

Author Contributions: Material synthesis, experimental design, writing Original draft, reviewing \& editing of paper was performed by Y.G. Analytic calculations and writing Original draft was performed by N.K.G. Crucial research components provided by J.B. Supervision and Funding acquisition performed by K.S.K. All authors discussed the results and contributed to the final manuscript.

Funding: This research was funded by ["Korea Institute of Civil engineering and building Technology" (KICT), Rep. of Korea], and grant number of [20190161-001].

Conflicts of Interest: The authors declare no conflict of interest.

\section{References}

1. Ahmaruzzaman, M. Adsorption of phenolic compounds on low-cost adsorbents: A review. Adv. Colloid Interface Sci. 2008, 143, 48-67. [CrossRef] [PubMed]

2. Spiridon, O.B.; Preda, E.; Botez, A.; Pitulice, L. Phenol removal from wastewater by adsorption on zeolitic composite. Environ. Sci. Pollut. Res. 2013, 20, 6367-6381. [CrossRef] [PubMed]

3. Villegas, L.G.C.; Mashhadi, N.; Chen, M.; Mukherjee, D.; Taylor, K.E.; Biswas, N. A short review of techniques for phenol removal from wastewater. Curr. Pollut. Rep. 2016, 2, 157-167. [CrossRef]

4. Adam, F.; Andas, J.; Rahman, I.A. A study on the oxidation of phenol by heterogeneous iron silica catalyst. Chem. Eng. J. 2010, 165, 658-667. [CrossRef]

5. Leal, T.W.; Lourenço, L.A.; de Brandão, H.L.; da Silva, A.; de Souza, S.M.A.G.U.; de Souza, A.A.U. Low-cost iron-doped catalyst for phenol degradation by heterogeneous Fenton. J. Hazard. Mater. 2018, 359, 96-103. [CrossRef] [PubMed]

6. Ahmed, S.; Rasul, M.G.; Brown, R.; Hashib, M.A. Influence of parameters on the heterogeneous photocatalytic degradation of pesticides and phenolic contaminants in wastewater: A short review. J. Environ. Manag. 2011, 92, 311-330. [CrossRef]

7. Esplugas, S.; Giménez, J.; Contreras, S.; Pascual, E.; Rodríguez, M. Comparison of different advanced oxidation processes for phenol degradation. Water Res. 2002, 36, 1034-1042. [CrossRef]

8. Kavitha, V.; Palanivelu, K. The role of ferrous ion in Fenton and photo-Fenton processes for the degradation of phenol. Chemosphere 2004, 55, 1235-1243. [CrossRef]

9. Alnaizy, R.; Akgerman, A. Advanced oxidation of phenolic compounds. Adv. Environ. Res. 2000, 4, 233-244. [CrossRef]

10. Miklos, D.B.; Remy, C.; Jekel, M.; Linden, K.G.; Drewes, J.E.; Hübner, U. Evaluation of advanced oxidation processes for water and wastewater treatment-A critical review. Water Res. 2018, 139, 118-131. [CrossRef]

11. Bao, T.; Damtie, M.M.; Wu, K.; Wei, X.L.; Zhang, Y.; Chen, J.; Deng, C.X.; Jin, J.; Yu, Z.M.; Wang, L.; et al. Rectorite-supported nano-Fe3O4 composite materials as catalyst for P-chlorophenol degradation: Preparation, characterization, and mechanism. Appl. Clay Sci. 2019, 176, 66-77. [CrossRef]

12. Bao, T.; Jin, J.; Damtie, M.M.; Wu, K.; Yu, Z.M.; Wang, L.; Chen, J.; Zhang, Y.; Frost, R.L. Green synthesis and application of nanoscale zero-valent iron/rectorite composite material for P-chlorophenol degradation via heterogeneous Fenton reaction. J. Saudi Chem. Soc. 2019. [CrossRef]

13. Vorontsov, A.V. Advancing Fenton and photo-Fenton water treatment through the catalyst design. J. Hazard. Mater. 2019, 372, 103-112. [CrossRef] [PubMed]

14. Zazo, J.A.; Casas, J.A.; Mohedano, A.F.; Gilarranz, M.A.; Rodríguez, J.J. Chemical pathway and kinetics of phenol oxidation by Fenton's reagent. Environ. Sci. Technol. 2005, 39, 9295-9302. [CrossRef] [PubMed]

15. Nidheesh, P. Heterogeneous Fenton catalysts for the abatement of organic pollutants from aqueous solution: a review. RSC Adv. 2015, 5, 40552-40577. [CrossRef]

16. Shukla, P.; Wang, S.; Sun, H.; Ang, H.-M.; Tadé, M. Adsorption and heterogeneous advanced oxidation of phenolic contaminants using Fe loaded mesoporous SBA-15 and $\mathrm{H}_{2} \mathrm{O}_{2}$. Chem. Eng. J. 2010, 164, 255-260. [CrossRef]

17. Soon, A.N.; Hameed, B. Heterogeneous catalytic treatment of synthetic dyes in aqueous media using Fenton and photo-assisted Fenton process. Desalination 2011, 269, 1-16. [CrossRef] 
18. Yan, Y.; Jiang, S.; Zhang, H. Catalytic wet oxidation of phenol with Fe-ZSM-5 catalysts. RSC Adv. 2016, 6, 3850-3859. [CrossRef]

19. Aleksić, M.; Kušić, H.; Koprivanac, N.; Leszczynska, D.; Božić, A.L. Heterogeneous Fenton type processes for the degradation of organic dye pollutant in water-The application of zeolite assisted AOPs. Desalination 2010, 257, 22-29. [CrossRef]

20. Martínez, F.; Calleja, G.; Melero, J.A.; Molina, R. Iron species incorporated over different silica supports for the heterogeneous photo-Fenton oxidation of phenol. Appl. Catal. B 2007, 70, 452-460. [CrossRef]

21. Gernjak, W.; Krutzler, T.; Glaser, A.; Malato, S.; Caceres, J.; Bauer, R.; Fernández-Alba, A.R. Photo-Fenton treatment of water containing natural phenolic pollutants. Chemosphere 2003, 50, 71-78. [CrossRef]

22. Martínez, F.; Calleja, G.; Melero, J.A.; Molina, R. Heterogeneous photo-Fenton degradation of phenolic aqueous solutions over iron-containing SBA-15 catalyst. Appl. Catal. B. 2005, 60, 181-190. [CrossRef]

23. Sashkina, K.A.; Labko, V.S.; Rudina, N.A.; Parmon, V.N.; Parkhomchuk, E.V. Hierarchical zeolite FeZSM-5 as a heterogeneous Fenton-type catalyst. J. Catal. 2013, 299, 44-52. [CrossRef]

24. Mirzaei, A.; Chen, Z.; Haghighat, F.; Yerushalmi, L. Removal of pharmaceuticals from water by homo/heterogonous Fenton-type processes - A review. Chemosphere 2017, 174, 665-688. [CrossRef]

25. Hartmann, M.; Kullmann, S.; Keller, H. Wastewater treatment with heterogeneous Fenton-type catalysts based on porous materials. J. Mater. Chem. 2010, 20, 9002-9017. [CrossRef]

26. He, J.; Yang, X.; Men, B.; Wang, D. Interfacial mechanisms of heterogeneous Fenton reactions catalyzed by iron-based materials: A review. J. Environ. Sci. 2016, 39, 97-109. [CrossRef]

27. Yang, Y.; Zhang, H.; Yan, Y. The preparation of Fe2O3-ZSM-5 catalysts by metal-organic chemical vapour deposition method for catalytic wet peroxide oxidation of m-cresol. R. Soc. Open Sci. 2018, 5, 171731. [CrossRef]

28. Romero-Sáez, M.; Divakar, D.; Aranzabal, A.; González-Velasco, J.R.; González-Marcos, J.A. Catalytic oxidation of trichloroethylene over Fe-ZSM-5: Influence of the preparation method on the iron species and the catalytic behavior. Appl. Catal. B 2016, 180, 210-218. [CrossRef]

29. Fabrizioli, P.; Bürgi, T.; Burgener, M.; van Doorslaer, S.; Baiker, A. Synthesis, structural and chemical properties of iron oxide-Silica aerogels. J. Mater. Chem. 2002, 12, 619-630. [CrossRef]

30. Navalon, S.; Alvaro, M.; Garcia, H. Heterogeneous Fenton catalysts based on clays, silicas and zeolites. Appl. Catal. B. 2010, 99, 1-26. [CrossRef]

31. Saifuddin, M.; Bae, J.; Kim, K.S. Role of Fe, Na and Al in Fe-Zeolite-A for adsorption and desorption of phosphate from aqueous solution. Water Res. 2019, 158, 246-256. [CrossRef] [PubMed]

32. Suho, K.; Gupta, N.K.; Bae, J.; Kim, K.S. Structural variations and generation of binding sites in Fe-loaded ZSM-5 and silica under the effect of UV-irradiation and their role in enhanced BTEX abatement from gas streams. J. Hazard. Mater. 2020, 384, 121274.

(C) 2019 by the authors. Licensee MDPI, Basel, Switzerland. This article is an open access article distributed under the terms and conditions of the Creative Commons Attribution (CC BY) license (http://creativecommons.org/licenses/by/4.0/). 